\title{
Rurality and Exclusion in Ordinary Level Mathematics in Zimbabwe: A Document Analysis
}

\author{
Simon Vurayai \\ University of Johannesburg, South Africa \\ https://orcid.org/0000-0001-9395-8880
}

\begin{abstract}
This conceptual paper fuses literature review and document analysis in examining the nexus between rurality and social exclusion in Ordinary level mathematics education in Zimbabwe. The paper utilizes Bourdieu's cultural capital theory to examine the content and context of mathematics problems in textbooks and examinations focusing on language and cultural experiences. Globally, rural education has been neglected and Zimbabwe is no exception. I argue that the role of nonmaterial deterrents like lack of cultural and language capital in achievement in mathematics education has not been accorded due attention. I conclude that the context of mathematics problems in textbooks and examinations is alien to rural learners. The readability of textbooks is also beyond the reach of many rural learners. I recommend that the mathematics curriculum should be inclusive of the diverse cultural experiences of learners and the language used should be intelligible to all. The mathematics educators and related stakeholders should know that every child is capable of doing mathematics hence all forms of social closure should be eradicated.
\end{abstract}

Keywords: mathematics; Ordinary level; rural areas; language; cultural capital; social exclusion

\section{Introduction}

The current structure of a six-year secondary education in Zimbabwe is two years of general education at Junior Level, two years leading to Ordinary Level Certificate in which students sit for examinations at the end of the fourth year, then two years of Advanced level with national examinations in the sixth year. Students' mathematical proficiency in Zimbabwe is normally used for making decisions regarding further schooling and job opportunities (Channon, McLeishSmith, Head, Macrae \& Chasakara, 2011), yet most pupils underperform in the subject particularly in the rural areas. I argue that rural learners have always been marginalized and excluded in education due to various factors such as poverty, language, cultural experiences, technological divide, and others (Mupa, 2015). 
Oscar Lewis, the founding father of the culture of poverty theory laments on the state and plight of a poor rural learner and admits that "...his environment is not only poverty-stricken in economic terms but also cultural terms. The catalogue of deficiencies of the culturally deprived child includes linguistic, experiential, cognitive, and personality deficiencies, and a wide range of substandard attitudes" (Haralambos \& Holborn, 2008, p. 632). I agree that beyond deficient material requirements, rural students are also subject to nonmaterial cultural deterrents in the teaching and learning of mathematics.

Considering that I am overwhelmed by the burden of rural learners, I am going to examine the possible impact of language and cultural experiences as factors of social exclusion in mathematics education. Specifically, this conceptual paper uses document analysis in which I examine the role of textbooks and past examination question papers in reinforcing the social exclusion of rural learners. I agree that there has been an attempt to promote equality of educational opportunities in Zimbabwe but mathematics education is still riddled with inequalities (Mupa, 2015). I examine whether those students also have access to mathematics education, particularly those in poor rural schools. Following the idea of Education for All (EFA), the National Council for Teachers of Mathematics (NCTM) (1998) advocates for the implementation of the Equity Principle in which all learners are given a chance to do Mathematics. I am motivated by the need to establishing the state of mathematics for all in poverty-stricken rural schools, particularly at Ordinary level (' $\mathrm{O}$ ' level), concerning the principles of inclusivity. Why specifically focusing on ' $\mathrm{O}$ ' level mathematics? ' $\mathrm{O}$ ' level mathematics proficiency in Zimbabwe is used as the basis for decisions regarding further schooling and job opportunity (Mupa, 2015; Nziramasanga, 1999). With specific reference to the value of mathematics in entrepreneurship, NCTM (1998) notes that employment opportunities in fields such as health care, construction, automanufacturing, and fashion design require a more sophisticated knowledge of mathematics. The learners who are enrolled and succeed in ' $\mathrm{O}$ ' level mathematics have the advantage of getting more access to highly rewarding occupational opportunities as compared to those who would have failed the subject(Channon et al., 2011). In this theoretical paper, I start by presenting the background and statement of the problem of rurality and exclusion in mathematics education. Bourdieu's cultural capital theory as the bedrock of this study is discussed together with brief existing literature on the effects of language and cultural experiences on learners' performance in mathematics education.

\section{Background to the problem}

The government of Zimbabwe, in 1980, was unfortunate to inherit from Britain a system that was skewed in favour of the white minority population in sectors such as economics, politics, and technology. A dualistic socio-economic system had a dominating white population that occupied the rich sectors such as mining, manufacturing industries, and commercial farms. Economically, there also existed, African peasants that lived in abject poverty, disease, and undeveloped infrastructure (Protracted Relief Programmes, 2012). In other words, Zimbabwe had rural areas that were characterized by peasant agriculture, and the urban income was characterized by large scale industries and transport services. Following independence, Zimbabwe introduced corrective measures of 
centralised economic planning and socialist-oriented policies. The government embarked on a programe of improving the lives of the population that was marginalized previously (Mavhunga, Madondo \& Phiri, 2009). The previously marginalised population refers to the socially excluded poor Zimbabweans who had limited access to education, particularly those in rural areas.

Towards the end of the first decade of independence, the Zimbabwean economy nose-dived as shown by most indicators such as the primary health care and education sectors whose standards were on the decline. The economy of Zimbabwe suffered a serious deterioration in the mid-1990s (Murisa, 2010). According to Nzingo (2010), the declining economy and the political crisis in the country gave rise to abject poverty. The social decline in rural areas entailed deterioration in the provision and quality of social services such as education and health.

The Zimbabwean rural areas, as has been previously captured (Mavhunga et al., 2009), are the most affected by poverty. They have challenges in areas such as road networks, health, safe water, sanitation, and food supply (Robertson, 2011). Previous studies (Nziramasanga, 1999; Mavhunga et al., 2009) reveal that pupils' academic performance in rural areas in Zimbabwe has been an area of concern. In mathematics education, Mupa (2015) notes that poor rural learners find it difficult to pass without adequate textbooks because they will not be able to see examples and can hardly share experiences on their own. Mupa (2015) further adds that Mathematics is a subject that requires material resources for the students such as graph books and mathematical sets which they struggle to afford. Studies on poverty and mathematics education in Zimbabwe have been broad and general and focusing on deficient tangible material resources(textbooks, graph books, calculators, etc) as the major cause of dismal performance (Chattaraj, 2020; Mupa,2015; Rammala, 2009). Very few studies have been focusing on nonmaterial resources like language and cultural experiences and this makes this study unique. Most previous studies have been centred on primary data, hence this study distinguishes from the rest as it relies on literature review and documentary analysis to draw inferences that can be added to existing findings. The study also utilised the benefits of document analysis as discussed in the methodology section of this paper.

\section{Statement of the problem}

Students' mathematics proficiency in Zimbabwe is often used for decisions regarding schooling and job opportunity (Channon et al., 2011), yet the pass rate in the poverty-stricken schools in rural areas is persistently catastrophic (Mupa, 2015). Given that rural learners are prone to various forms of inequalities (material and nonmaterial), I am motivated to examine how textbooks and past examination question papers reinforce social exclusion particularly through language and cultural experiences.

\section{Pierre Bourdieu and the cultural capital theory}

Pierre Bourdieu is a neo-Marxist Frenchman who developed the cultural capital theory. Bourdieu argues that education in a capitalist society secures cultural continuity and barricades poor children's access to higher learning. Rather than 
culture in totality, regardless of class as claimed by functionalists (Haralambos \& Holborn, 2008), it is an exclusive vehicle for middle-class culture as a definitive, overriding construct (Haralambos, Holborn \& Heald, 2014). If Bourdieu is right that affluent children bring relevant cultural capital to school, I infer that mathematics instruction may be doing exactly the privileging exercise postulated by his theory. It attempts to make mathematics more assimilable to 'lessprivileged' classes and does the exercise while slightly disguised. It leaves the less-privileged worse off since the gap between them and the privileged may even widen in the process of remediation. This is because it is more than likely that the privileged class has developed a natural aptitude, aided and abetted by a large array of acclimatising/facilitating mechanisms at its disposal that naturally tend to put it in the lead. Bourdieu's theory was helpful in the choice of documentary analysis as a data-gathering technique to ascertain the nexus between mathematics teaching and learning and rural learners' cultural experiences.

Verbal skills and mental processes that give privileged children an advantage (Applebaum \& Chambliss, 1995) referred to by Bourdieu as cultural capital, enables learners to decode education and show flair and excellence due to prior conditioning assimilated in the earliest years of life during primary socialisation (Blackledge \& Hunt, 1985). The less-privileged class experience disorientating culture shock when exposed to the 'normal' educational world of their privileged peers. The disorientation of cultural shock naturally accompanies entry into an unfamiliar world (Macionis, 1989). Assuming, therefore, that Bourdieu is right 'it stands to reason' (i.e. mutatis mutandis) that less-privileged learners are bound to find mathematics difficult.

According to Bourdieu (Haralambos et al., 2014), the affluent groups effectively oppress their less privileged peers by dictating their understanding of the world as final and inarguable, and, therefore, arrogantly imposing penalties on less privileged groups for not deferring (whether willfully or by default) to their selfproclaimed preconception of the world (Haralambos \& Holborn, 2008). As noted above, besides securing middle-class cultural continuity, the function of education is to barricade the less privileged from entering higher levels of education (cf. Bourdieu; (Bilton, Bonnet, James \& Sheared, 1989). Barrier mechanisms are examination failure and self-elimination (Haralambos \& Holborn, 2008). The barriers may be depicted by high low pass rates and high dropout rates in mathematics in rural areas. The efficacy of the first of these barriers resides in the lack of cultural capital by the bulk of learners in rural schools who are less-privileged. The second, related barrier is the dropout rate, which makes failure self-induced, again for lack of cultural capital, which imparts the appearance of an unscalable height to the prospect of entering the realm of higher education. In these circumstances, failure at mathematics examinations seems preordained for the less-privileged who are conditioned to believe that the system will not tolerate their entry into higher levels of mathematics education (Haralambos et al., 2014). The point is driven home by Bourdieu in the following statement:

"As pupils move up the ladder, those from the dominated class are progressively eliminated and shunted into less prestigious forms of knowledge. On the other hand, the primary socialization of those from the 
dominant class provides them with cultural capital which translates into academic and eventually occupational success "(Bilton et al., 1989, p.33).

I apply Bourdieu's assumptions to mathematics by logical extension, with the result that these views could be applied towards determining the influence attributable to the language and cultural capital on mathematics teaching and learning in rural schools. Although Bourdieu did not specifically refer to mathematics education and rural contexts in his theory, I assume that this claim may mean that mathematics education is tilted in favour of the culture of the dominant groups and marginalizes the culture of the poor rural children.

\section{Cultural experiences of learners and access to mathematics education in rural contexts}

Snowman, McCown and Biehler (2001) observed that middle-class children are exposed to a variety of experiences and these experiences accumulate and make school learning more familiar and easier than it would be otherwise. For instance, Smith and Noble (1995) cited in Haralambos and Holborn (2008) observe that working-class children fail to afford shopping or educational trips, and, as a result, they may fall behind their school work. The common observation here is that learning also takes place beyond the classroom. As such, affluent children bring to school relevant experiences that aid their learning of mathematics than their non-affluent counterparts. The curriculum is designed in such a way that it alienates the rural learner who cannot use the local examples to relate to the curriculum context (Rammala, 2009). As a result, rural children may fail to understand the context in which some mathematics problems are presented leading to failure.

Learning in mathematics education depends on the ability of students to connect new ideas with what they already know or experience. New knowledge will hardly make meaning unless it connects or relates well the existing knowledge (Crawford, 2001; Compton, Fielding \& Scott, 2007; Zengin, 2019). Richard Skemp identifies two types of understanding in mathematics as instrumental and relational (Compton, Fielding \& Scott, 2007). Instrumental understanding entails learning and comprehending the rules of mathematics and being able to apply them while relational understanding means connecting new ideas with existing ones. Mwakapenda (2008) acknowledges the importance of relational understanding in that;

"...connections are at the heart of the definition of mathematics. These connections are concerned with what mathematics is: where it comes from - human activity, a construction, development and contestation that is time- and socially-dependent - and what it does: problem-solve and understand the world and daily living. Mathematics is not about the reasoning for its own sake. It is concerned with reasoning, symbolizing, and thinking - processes that are connected to activities and problems of the social, physical, and mathematical worlds involving human practices in all cultures". ( $p 190)$. 
In a more recent observation, Siregar and Siagian (2019) confirm that; In learning mathematics mathematical connections ability is one of the mathematical abilities that must be possessed by students. The strong connection between concepts in mathematics implies that mathematical connections ability also contains other mathematical aspects or vice versa. Viewing mathematics as a whole is very important in learning and thinking about connections between topics in mathematics. ( $p 1)$.

By implication, I argue that it is relational understanding which is more important to the learners since they can make meaningful connections between what they know and what they learn in mathematics.

Bourdieu cited in Haralambos et al. (2014) aver that the affluent children have familiar cultural experiences and the progress in education is directly influenced by the culture the child gets from the family. On the other hand, working-class children underperform in education. After all, they experience culture shock because they lack related experiences. Bourdieu cited in Bol and Berry (2005) further states that there is a mismatch between poor student, home culture, and the culture valued by the school. According to Bush (2005), mathematics education has virtually ignored rural contexts. Graven (2014) observes that irrespective of corrective reforms and innovations in mathematics education, rural learners still experience social exclusion in mathematics education that matters. The mathematics that many students learn is connected to neither them nor their communities. From the studies above, I theorize that the language and contexts of some mathematics problems are not related to the experiences of the rural learners and as a result, they underperform.

\section{Language and access to mathematics education in rural contexts}

Language, which the child brings from home is an important resource in learning. Durkin (1991) cited in Nziramasanga (1999 p. 331) puts forth that "mathematics education begins and proceeds in language, advances and stumbles because of language and its outcomes are often assessed in language". An earlier study by Ezewu (1983) reveals that fundamental to the learning of all other subjects is the mastery of good English as it is the language of instruction in English speaking nations. Bourdieu's cultural capital theory states that the language of education is closer to that of the dominant class than that of any other class. The relevant language is a key in which children from the dominant class internalize during primary socialization and they use it to unlock the message transmitted in the classroom (Haralambos \& Holborn, 2008). Children with high socioeconomic backgrounds have a linguistic advantage which they will use in learning (Nurul \& Yunus, 2020). These studies note that in English speaking nations, those students from affluent background have an advantage in that they are fluent in the English Language which is also a language of instruction. As a result, it becomes very easy for them to master mathematics concepts when they are taught in English.

Berns (2010) also acknowledges that parents from middle socioeconomic status are important role models in the education of their children. I infer that those parents who speak and understand English well have their children better placed for success in mathematics education. A good understanding of the English 
language helps learners to engage in complex tasks and understand word problems and instructions in textbooks and examinations (Sao, 2008; Musaisia, Nakhanu \& Wekesa, 2012; Bethel 2016; Magableh \& Abdullah, 2020). In other words, the English language can be a tool for inclusion or exclusion in mathematics education for rural learners (Mtisi \& Maposa, 2016). Ledibane, Kaiser and Van der Walt (2018) acknowledge that:

"We teach through the medium of language. It is our major means of communication. Learners build understanding as they process ideas through language. We diagnose and assess learners' understanding by listening to their oral communication and by reading their mathematical writings." (p1).

In a related observation, Graven (2014) avers that the language used in mathematics textbooks is far removed from non-affluent students' everyday speech and this becomes a major force of alienation in its own right. Berns (2010) also notes that children from a higher socio-economic background with good language also a good mastery of the English language which aids them in understanding word problems and several tasks in mathematics instruction. A poor command of the English Language results in challenges in performing mathematics tasks. Teachers may also hold low expectations on those learners with a poor command of the English Language to the extent that they are given less attention during instruction (Kaur, 2013; Chattaraj, 2020).

In more recent studies, Robertson and Graven (2020) put forth:

"...the power of language to either include or exclude certain groups of students from genuine opportunities for mathematical sense-making. Should not be underestimated... because English is widely perceived as the language of opportunity, it is, by grade 4, overwhelmingly the chosen language of learning and teaching. The epistemological and pedagogical consequences of this choice are evidenced in the poor performance of the country's students on national and international assessments of mathematical proficiency. The dominance of a single language of power as the medium for education has major implications for access to learning for those who do not speak this language at home and who are often already marginalized in terms of access to social and economic goods...In this respect fluency in the dominant language of learning, teaching, and assessment is a key issue for inclusivity and equity." (p1).

I infer that has the power to influence performance and pedagogy. It is a tool that can determine who is to be included or excluded in mathematics education. It is therefore important to consider the point that the language that the learners bring from home is a key factor on which further learning will rest upon.

In Zimbabwe, Nziramasanga (1999) admits that:

"For the average Zimbabwean child, the use of the English language in mathematics education is far more complex than an education system has cared to admit. Many pupils have problems with English. If mathematics is intricately related to language, in this case, English, there can be no doubt that many pupils' mathematical development is being retarded on account of language and not lack of mathematical ability." (p337). 
From the above, I argue that English Language proficiency is a critical element in teaching and learning of mathematics. In this study, I examine the contexts of mathematics problems in textbooks and examinations concerning their cultural and language experiences of poor rural learners. I further establish the extent to which the experiences of rural learners are connected to the teaching and learning of various mathematics topics in the ' $\mathrm{O}$ ' level syllabus. I also examine the specific mathematics topics in the ' $\mathrm{O}$ ' level syllabus and textbooks that are presented in a difficult language, in which children living in rural poverty may find it difficult to comprehend.

\section{Methodology}

In this study, I used document analysis. I found it important to conceptualise document analysis and discuss its benefits concerning this study. Document analysis entails

"... a systematic procedure for reviewing or evaluating documents - both printed and electronic (computer-based and Internet-transmitted) material. Documents that may be used for systematic evaluation as part of a study take a variety of forms. They include advertisements; agendas, attendance registers, and minutes of meetings; manuals; background papers; books and brochures; diaries and journals; event programs (i.e., printed outlines); letters and memoranda; maps and charts; newspapers" (Bowen, 2009, p. 27).

It is important to note that document analysis is a process that involves skimming (superficial examination), reading (thorough examination), and interpretation of content to provide answers to research questions (Parveen \& Showkat, 2017). In this study, I examined the content and context of $\mathrm{O}^{\prime}$ level mathematics and came up with an interpretation of the state of social exclusion it presents to rural students. I followed the steps below as suggested by Parveen and Showkat (2017);

(a) Identify your research question/objective.

(b) Select your sample

(c) Skim the material selected through the aforementioned procedure and make a list of main themes you plan to analyse.

(d) Can classify the content based on these themes or categories. (p38).

With the main objective of examining the extent to which the rural learners are excluded in mathematics education, I selected a sample of $\mathrm{O}^{\prime}$ level mathematics textbooks and past examination question papers. I skimmed through the content which I classified focusing on themes related to the exclusion of rural learners based on language and cultural context. The detail is presented in the next section.

I utilised several advantages by choosing document analysis as an approach in this study. It is important to note that document analysis offers the following advantages as simplified by (Bowen ,2009);

- Efficient method: Document analysis is less time-consuming and therefore more efficient than other research methods. It requires data selection, instead of data collection.

- Availability: Many documents are in the public domain, especially since the advent of the Internet, and are obtainable without the authors' permission. This makes document 
analysis an attractive option for qualitative researchers. Locating public records is limited only by one's imagination and industriousness.

- Cost-effectiveness: Document analysis is less costly than other research methods and is often the method of choice when the collection of new data is not feasible. The data (contained in documents) have already been gathered; what remains is for the content and quality of the documents to be evaluated.

- Lack of obtrusiveness and reactivity: Documents are 'unobtrusive' and 'non-reactive' that is, they are unaffected by the research process.

- Stability: As a corollary to being non-reactive, documents are stable. The investigator's presence does not alter what is being studied. Documents, then, are suitable for repeated reviews.

- Exactness: The inclusion of exact names, references, and details of events makes documents advantageous in the research process.

- Coverage: Documents provide broad coverage; they cover a long period, many events, and many settings (p31).

Document analysis proved to be very effective in this study especially when travelling and contact with the respondents was difficult due to the global measures to curb the spread of the COVID1-19 pandemic. I simply collected the data which I analysed concerning the existing literature and the research questions to come up with the findings for the study.

\section{Document analysis: Cultural experiences and the context of mathematics problems}

A documentary analysis in this section focuses on the nexus between the context of mathematics problems in main textbooks and past examination question papers and the experiences of rural learners. Specifically, I analyse the main textbooks used in the Zimbabwean schools studied which are: Focus on Mathematics Book 4, and New General Mathematics Books 4 and 3. These are the main textbooks that are used for teaching and learning at ' $O$ ' level mathematics in Zimbabwe. These textbooks have been approved by the ministry of education as the best in line with the requirements of the current syllabus. From the textbooks, my interest is the context in which the problems are presented concerning whether the students from poor rural schools could comprehend them given their poverty and cultural deprivation. I also analyse the past examination question papers using the same approach with the textbooks. I classify the questions in such a way that those from the textbooks are presented first followed by questions from past examinations papers. In my document analysis (scrutiny of textbooks and exam papers) I note that settings of mathematics problem formulations are foreign to students' experiential world (poor rural settings), and this places them at a significant disadvantage, compared to the more culturally privileged and affluent suburban, and peers(see the 8 examples). 
Example 1:

i. $\quad$ Thomas and Sam have played each other at tennis 12 times. Thomas has won 10 times. They play each other in a competition. Find the probability that

a) The match will be drawn

b) Tendai will win

c) Either Tendai or Samuel will win

Solution:

a. Tennis matches are either won or lost. They are never drawn. Probability of a draw $=0$.

[Source: The New General Mathematics Book Four page 158, example 1]

Tennis courts are unknown in the vicinity of rural students with the result that effectively, the question is misleading in that it calls for some familiarity with the rules of the game. Students would, therefore, understandably be at a loss to provide the correct answer. But even so, knowing the answer would say nothing about their mathematical ability or insight since knowing the answer required familiarity with rules, not mathematical insight (Siregar \& Siagian, 2019; Mwakapenda, 2008). Usually, the game is associated with rich elite and urban schools in Zimbabwe. Since most students in rural areas do not play tennis, they do not know the rules, that for example, tennis matches are never drawn, they are either won or lost. Due to a lack of relevant experiences with tennis matches and related rules, most rural students are more likely to face challenges in providing the solution. In another context taken from Focus on Mathematics Book 4 page 307, example 4, read as:

Example 2

A furniture firm offers a lounge set for $\$ 21000$ cash or a deposit of $\$ 6000$ and 12 monthly installments of $\$ 1500$ each.

(a) Determine the total amount due and payable if the suite is bought on credit (installment plan).

(b) What is the difference in price between a transaction on terms (installment plan), and a cash transaction if the price is calculated less deposit?

Again, the formulation of this problem does not fall within the range of relevant parents' experiential world since most do not qualify for credit transactions, thus leaving children at a loss as to relate to the particulars of the transaction presupposed in the problem formulation, and therefore unable to provide an answer to the question. In this instance, the setting places children in poor rural settings at a disadvantage. Most parents of the students in rural schools are unemployed, therefore, do not qualify for higher purchase terms and conditions. By implication, they cannot purchase big furniture sets such as the lounge suite, suggesting that their children rarely interact with statements of account. Such lack of experience could imply problems in interpreting statements of accounts on the part of the children. Given such a problem, poor rural students may struggle to interpret the context to understand the concepts behind hire purchase terms and conditions, before providing a correct solution. 


\section{Example 3}

a) Mr. Moyo's water meter reading for the end of March and April was 15674 and 15718 , respectively. Given that there is a fixed monthly charge of $\$ 12.50$, the unit charge is 62 cents and rates work were charged at $10 \% /$ dollar, find the amount Mr. Moyo will be charged for water used in April [Source: Focus on Mathematics Book 4 page 328, example 4]

Again, students in rural areas are not exposed to the concepts of paying for water use at all, let alone at a fixed monthly charge. Therefore, they would again be at a disadvantage caused by unfamiliarity, this time with the conceptual framework of municipal services and routine payments made to the supplier. Unfamiliarity, might, therefore, tend to derail their attempts to deal with the problem. Most rural schools do not have tapped water with meter readers. The students have probably never been exposed to water units and water bill statements. Such a lack of prior knowledge of concepts like fixed monthly charge, unit charge, and rates work could cause problems in their interpretation of water bill statements. In their impoverished areas, most rural learners would not be able to conceptualize this and other related questions.

Example 4:

The following graph represents the acceleration of a car that starts from rest in $1^{\text {st }}$ gear and then changes to second gear at an appropriate speed.

(a) Give the acceleration rate and distance covered in $1^{\text {st }}$ gear.

(b) If the car travels $54 m$ in $2^{\text {nd }}$ gear, find the value of $v$ and the acceleration rate achieved in that gear.

[Source: New General Mathematics Book 3 page 280 number 8]

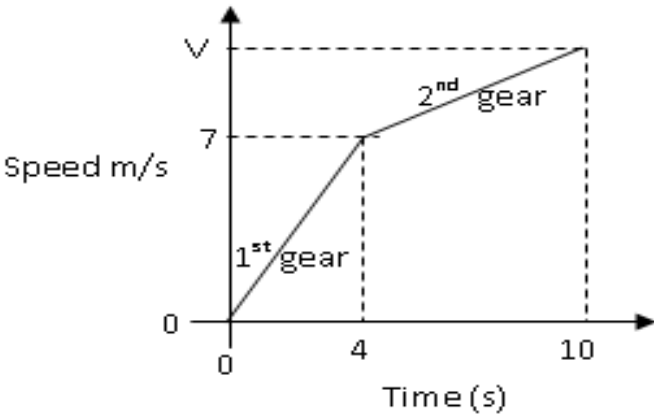

Most students in rural schools have no cars at home, suggesting that they have no prior knowledge of how gears work. Those who have cars at home have prior experience of how car gears work and are better placed to interpret this question. When applied to kinematics as in the problem above, the students would struggle with the context before the concept and the doing of mathematics. Unfamiliarity with motor vehicles and their performance characteristics (car ownership is rare among rural poor) would leave students unable to relate intelligently to the question and, therefore, at a loss as to answer it correctly. 
Example 5:

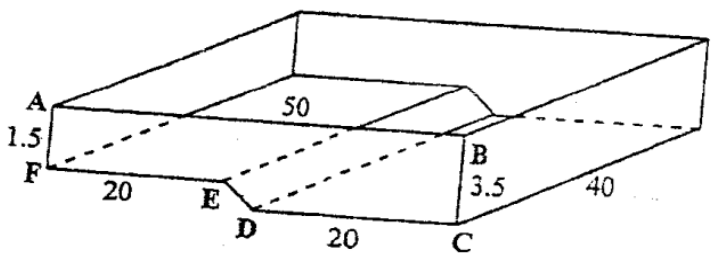

The diagram shows a swimming pool of uniform cross-section $A B C D E F$, length $50 m$, and breadth $40 \mathrm{~m}$.

$A B=50 m, B C=3,5 m, D C=F E=20 m, A F=1,5 m$, and $B \hat{A} F=A \hat{F} E=B \hat{C} D=A \hat{B} C$ $=90^{\circ}$

(a) Calculate

(i) The cross-sectional area $A B C D E F$

(ii) Swimming-pool capacity in kilolitres

(iii) The length of $D E$

(b) The vertical walls of the pool area to be painted. Given that 7 litres of paint are needed to cover $10 \mathrm{~m}^{2}$ of wall surface and that the paint is sold in 5 litre containers at \$27each.

Calculate

(i) Total area to be painted

(ii) Number of containers of paint required; [3]

(iii) Financial consideration implied. [1]

[Source: Mathematics Paper 2 June 2010 number [11]

Most rural schools nor the communities surrounding them have no swimming pools, which are status symbols in Zimbabwe. Students would, therefore, be contextually be confused with the question since swimming-pools are not part of their experiential world. The learners who have never seen a swimming pool have no obvious understanding of the context and the related concepts as compared to the affluent children who have the day to day experiences with swimming pools. Such lack of prior experience or knowledge of swimming pools could imply problems in their interpretation of the cross-sectional area of the swimming pool and other related questions above, for example, they might mistakenly include the top of the figure representing the pool as a surface to be painted merely because they are unfamiliar with the phenomenon as a whole.

The examples above are a small sample of numberless questions of the same kind that are beyond the ken of the rural poor, who need to understand the context to visualize the situation successfully and apply their minds to the particulars of the question within the parameters of the envisaged context. As noted (Graven, 2014; Zengin, 2019) students from a poor rural background are disadvantaged by the task of overcoming the hurdle of understanding the context or setting first, and only then, within the relevant contextual parameters, address the mathematical particulars of the problem at issue. In a sense, therefore, questions such as those considered above are coded, and the rural poor lack the key to the code, unlike their privileged peers, because they are unfamiliar with the contextual framework of the questions put to them. They are, therefore, effectively locked out of the inner 
sanctum of the contextual world of their privileged peers. Hence, their underperformance at mathematics is not because of an innate incapacity but is because of poverty, a factor beyond their control.

9. Documentary analysis: Language demands in mathematics education. The documentary analysis also indicates several long and wordy questions from textbooks and past examination papers which demand proficiency in the English Language (see examples 6-8).

Example 6

i. The mortgage rates go up from $17 \%$ to $18 \%$. What difference is this going to make to someone who has a mortgage? Answer the following questions to obtain some idea of the difference it will make and the different ways of coping with the increase. Repayment started recently so the amortisation of capital is still negligible. It would be advisable to answer this question with the aid of a calculator.

(a) A man has a loan of $\$ 40$ 000. At present he is paying it off over 20 years and the interest rate is $17 \%$.

(i) Calculate his monthly repayment.

(ii) Calculate the total amount he would pay during 20 years at $17 \%$.

(iii) If the interest goes up to $18 \%$, calculate the new monthly repayment if the loan is still to be paid off in 20 years.

(iv) Calculate the new total amount he will pay for 20 years at $18 \%$.

(v) Compute the percentage increase in the monthly repayments.

(vi) Compute the percentage increase in the total amount repaid.

(vii) If he decides that rather than pay the whole monthly increase he will reschedule his loan so that it is now repayable over 25 years, calculate the monthly repayment at $18 \%$ over 25 years.

(viii) Calculate the total amount repaid over 25 years in this case.

(ix) Calculate the percentage increase in monthly repayments from $17 \%$ over 20 years to $18 \%$ over 25 years.

(x) Calculate the percentage increase in total payment from $17 \%$ over 20 years to $18 \%$ over 25 years.

[Source: Focus on Mathematics Book 4 page 341 number 21]

The question above is too long and wordy to the extent that the students with a poor command of the English language are more likely to get confused. Eventually, such students would fail to solve the questions in the problem (Magableh \& Abdullah, 2020). Aspects of this question on mortgage and amortization of capital are unfamiliar to the students from poor rural backgrounds. Students are declared incapable of coping with the level of formulation from the viewpoint of English proficiency, exacerbated by the 
multifaceted, or rather hierarchical nature of the problem. For example, the successive steps in answering the question depended on producing a correct answer in dealing with the preceding step, so an error at the first step precluded the possibility of earning marks for subsequent steps which, perforce, would proceed from a wrong premise in each instance. Besides that, the student is doubly disadvantaged because the context of the problem is alien to the student's experiential world, with the result that unfamiliarity would tend to throw him/her mentally off-balance.

\section{Example 7}

A shopkeeper has two brands of soft drinks namely Kula and Sundown, which are packed in cans of identical size. He intends to order fresh supplies and finds that he has room for up to 1000 cans. He knows that Sundown is more popular and so proposes to order at least twice as many cans of Sundown as Kula. He wishes, however, to have at least 100 cans of Kula and not more than 800 cans of Sundown. Taking $x$ to be the number of Kula and $y$ to be the number of cans of Sundown which he orders, write down the four inequalities involving $x$ and/or $y$ which satisfy these conditions.

(a) The part $(x ; y)$ represents $x$ cans of Kula and $y$ cans of Sundown. Using the scale of $1 \mathrm{~cm}$ to represent 100 cans on each axis construct and indicate clearly by shading the unwanted regions, the region in which $(x ; y)$ must lie.

(b) The profit on a can of Kula is $3 c$ and on a can of Sundown is 2c. Use your graph to estimate the number of cans each that the shop keeper should order to maximise his/her profit.

[Source: New General Mathematics Book 4 page 147 number 10]

\section{Example 8}

You should answer this question on a sheet of graph paper.

Mr. Hove manufactures tables and chairs using softwood and hardwood. A table requires $5 m$ of softwood and $3 m$ of hardwood. A chair requires $3 m$ of softwood and $4 m$ of hardwood. $M r$. Hove has $45 \mathrm{~m}$ of softwood and $40 \mathrm{~m}$ of hardwood. Consider $x$ to represent the number of tables made and $y$ to represent the number of chairs made.

(a) Using the above information, write down the inequalities which satisfy these conditions.

(b) For Mr. Hove to make a profit, he should manufacture more than 2 tables and at least 4 chairs. State the two inequalities which satisfy these conditions. [2]

(c) The point $(x ; y)$ on the graph represents $x$ tables and $y$ chairs manufactured. Using a scale of $2 \mathrm{~cm}: 2$ tables on the $x$-axis and $2 \mathrm{~cm}: 2$ chairs on the $y$-axis, draw the axes for $0 \leq x \leq 16$ and $0 \leq y \leq 16$ indicate the regions in which $(x ; y)$ should lie.

(d) Write down all possible combinations which give the maximum number of tables.

[Source: Mathematics Paper 2 June 2008, number 12] 
Examples 7 and 8 above are also too long and wordy, as such, could confuse those students with a weaker comprehension of the English language. The evidence has been shown before from the studies by Bethel (2016), Magableh and Abdullah (2020) and Nurul and Yunus (2020). By implication, students could experience problems in interpreting the question into accurate graphical work. The examples cited above are just but a few from ' $\mathrm{O}$ ' level mathematics past examination question papers and ' $\mathrm{O}$ ' level mathematics textbooks in current use. As noted above, such long and wordy questions are more likely to pose a challenge to most poor rural students who have weaker comprehension of the English language. The examples cited above typify previous ' $\mathrm{O}$ ' level examination papers from which they were taken, therefore, the poor rural students to whom they are presented typically perform poorly at mathematics education.

\section{Mapping way forward}

The problem affecting rural students is the fact that besides having to deal with the bare facts of mathematical problems that severely challenge their mathematical skills and proficiency in the first place, they are wildly unfamiliar with the language and contexts in which mathematical problems are presented to them. This unfamiliarity, therefore, presents a mental barrier that had to be overcome in addition to the challenge to their mathematical ability - a double burden, compared to their more fortunate peers. I proffer the suggestion that mathematics textbooks and examinations should have multicultural and diverse contexts to cater for the heterogeneous society. The readability of texts and questions should also be accommodative so that learners from diverse contexts of the multilingual society equally enjoy the opportunity to do mathematics.

\section{Summary and conclusion}

The foregoing paper employs Bourdieu's cultural capital theory to guide in document analysis on how language and cultural capital influence achievement in mathematics education by rural learners. The cultural capital theory was considered to determine the possibility that, in the instances under review, the education system is biased in favour of the dominant culture, thus, foregrounding that culture at the expense of socially eliminating the lesser culture (ie. representatives who lack 'cultural capital'). It seems reasonable to conclude that mathematics education in the chosen setting conforms essentially to the position of Bourdieu, namely, that where mathematics education is concerned, middleclass children routinely find themselves on familiar territory. The rural students lack the relevant cultural experiences that place them in a privileged context in which mathematics problems are presented. Rural learners bear a double burden in their quest for mathematical knowledge because they have to come to terms with the shockingly unfamiliar context and language first, and then assimilate within that context, the mathematical knowledge presented to them. In these circumstances, they are likely to learn by rote without truly internalising the conceptual framework at issue, with the result that their knowledge is not operationalised and cannot be applied in practice or linked to prior knowledge. Learning that cannot be applied is meaningless to the learner. Rural learners' problems in comprehending the English language could lead to difficulties in learning mathematics because the readability of 'O' Level Mathematics textbooks and examinations word problems were found to be too high for them. 


\section{References}

Applebaum, R. P., \& Chambliss, W. J. (1995). Sociology. New York: Harper and Collins. Berns, R. M. (2010). Child, Family, School and Curriculum, Belmont: Wordsworth.

Bethel, G. (2016) Mathematics Education in SubSaharan Africa: Status Challenges and Opportunities: The World Bank Washington DC.

Bilton, I., Bonnet, K., James, F., \& Sheared, K. (1989). Introduction to Sociology. London: MacMillan.

Blackledge, D., \& Hunt, B. (1985). Sociological Interpretation of Education. London: Groomhelm.

Bol, L., \& Berry, R. Q. (2005). Secondary Maths Teachers' Perception of the Achievement Gap. North Carolina: University of North Carolina Press.

Bowen, G. (2009). Document Analysis as a Qualitative Research Method. Qualitative Research Journal, 9(2), 27-40. https:// doi.org/10.3316/qrj0902027

Bush, W. S. (2005). Improving research on mathematics learning and teaching in rural contexts. Journal of Research in Rural Education, 20(8). Retrieved from http://jrre.psu.edu/articles/20-8.pdf

Channon, J. B., McLeish-Smith., A., Head, H. C., Macrae, M. F., \& Chasakara, A. A. (2011). New General Mathematics Book 3. Essex: Longman.

Channon, J. B., McLeish-Smith., A., Head, H. C., Macrae, M. F., \& Chasakara, A. A. (2011). New General Mathematics Book 4. Essex: Longman.

Chattaraj, D. (2020). Strategies for Facilitating Listening Skills among Foreign Language Learners in US Universities. International Journal of Learning Teaching and Educational Research, 19(4),150-169. https://doi.org/10.26803/ijlter.19.4.10

Compton, A., Fielding, H., \& Scott, M. (2007). Supporting Numeracy. London: Paul Chapman Publishing.

Crawford, M. L. (2001). Teaching Contextually: Research Rationale and Techniques for Improving Student Motivation and Achievement in Mathematics and Science. Texas: CCI Publishing.

du Preez, M. (2018). The factors influencing Mathematics students to choose teaching as a career. South African Journal of Education, 38(2). https:// doi.org/10.15700/saje.v38n2a1465

Ezewu, E. (1983). Sociology. Lagos: Longman.

Graven, M. H. (2014). Poverty, Inequality and Mathematics Performance: The case of South Africa's Post Apartheid Context. ZDM Mathematics Education, 46(7), 10391049. https://doi.org/10.1007/s11858-013-0566-7

Haralambos, M., \& Holborn, M. (2008). Sociology: Themes and Perspectives. London: Collin Unwin.

Haralambos, M., Holborn, M., \& Heald, M. (2014). Sociology: Themes and Perspectives. London: Collin Unwin.

Kaur, R. (2013). Rural Education in India. Education Blogs. Retrieved from: https://www.mapsofindia.com/my-india/education/india-needs-educationespecially-rural-education

Ledibane, M., Kaiser, K., \& Van der Walt, M. (2018). Acquiring mathematics as a second language: A theoretical model to illustrate similarities in the acquisition of English as a second language and mathematics. Pythagoras, 39(1), a347. https://doi.org/10.4102/ Pythagoras.v39i1.347

Macionis, J. J. (1989). Sociology. London: Prentice-Hall.

Magableh, I. S. I., \& Abdullah, A. (2020). Effectiveness of differentiated instruction on primary school students' English reading comprehension Achievement. 
International Journal of Learning, Teaching and Educational Research, 19(9), 20-35 https://doi.org/10.26803/ijlter.19.3.2

Mavhunga, D. P., Madondo, M., \& Phiri, M. (2009). Education for All in Zimbabwe: A Mirage? Zimbabwe Journal of Educational Research, 21(1), 25-47. https://doi.org/10.4314/zjer.v21i1.44066

Mtisi, N., \& Maposa, C. (2016). Challenges Encountered in the Teaching and Learning of Natural Sciences in Rural Schools in South Africa. Journal of Social Science, 47(1), 58-67. https://doi.org/10.1080/09718923.2016.11893544

Mupa, P. (2015). Foundation for success in the teaching of $O$ level mathematics in rural secondary Schools in Masvingo District. Journal of Education and Practice, 6(19), 133-139.

Musaisia, M. A., Nakhanu, B. J., \& Wekesa, W. D. (2012). Investigation of factors that influence syllabus coverage in Secondary School Mathematics in Kenya. International Journal of Humanities and Social Sciences, 2(15), 31-34.

Murisa, T. (2010). Social Development in Zimbabwe. Harare: DFZ.

Mwakapenda, W. (2008). Understanding connections in the school mathematics curriculum. South African Journal of Education, 28(2), 189-202. https:// doi.org/10.15700/saje.v28n2a170

National Council for Teachers of Mathematics [NCTM]. (1998). Standards of Teaching Mathematics. Reston: VA.

Nsingo, E. (2010). Zimbabwe Now a Factory of Poverty. Harare: National Statistical Agency.

Nurul, A. B. A., \& Yunus, M. M. (2020). Undergraduates Student Perceptions' of Social Networking Sites to Improve English Writing Skills in Malaysia. International Journal of Learning, Teaching and Educational Research, 19(9), 329-351. https:// doi.org/10.26803/ijlter.19.3.18

Nziramasanga, C. (1999). Zimbabwe Report on the Presidential Commission of Inquiry into Education and Training. Harare: Government Printers.

Parveen, H., \& Showkat, N. (2017). An Integrative Approach to Content Analysis. The Content Analysis Guidebook, 36-69. https://doi.org/10.4135/9781071802878.n2

Protracted Relief Programme. (2012). Understanding Drivers of Poverty in Zimbabwe. Harare: PRP.

Rammala, M. S. (2009). Factors contributing Towards Poor Performance of Grade 12 learners at Manosh and Mokwatedi High Schools (Med Dissertation). Turfloop Graduate School of Leadership, Gaborone.

Robertson, J. (2011). Salaries of Ordinary Zimbabwean Far Below the Poverty Datum Line. Harare: National Statistical Agency.

Robertson, S., \& Graven, M. (2020). Language as an including or excluding factor in mathematics teaching and learning. Mathematics Education Research Journal, 32, 77-101. https:/ / doi.org/10.1007/s13394-019-00302-0

Sao, L. Y. T. (2008). Barriers to learning mathematics in rural secondary schools (Med Psychology thesis). University of Stellenbosch.

Siregar, R., \& Siagian, M, D. (2019). Mathematical connection ability: teacher's perception and experience in learning. International Seminar on Applied Mathematics and Mathematics Education IOP Conf. Series: Journal of Physics: Conf. Series, 1315. Cimahi, Indonesia. https:// doi.org/10.1088/1742-6596/1315/1/012041

Snowman, J., Mc Cown, R., \& Biehler, R. (2001). Psychology Applied to Teaching. Belmont: Wardsworth.

Zengin, Y. (2019). Development of mathematical connection skills in a dynamic learning environment. Education and Information Technologies, 24(3), 2175-2194. https://doi.org/10.1007/s10639-019-09870-x 